\title{
Human Agency and Its Discursive Practices
}

\author{
Qiuming Lin \\ Faculty of English Language and Culture \\ Guangdong University of Foreign Studies, Guangzhou, China \\ Tel: 86-137-9811-7687Ｅ-mail: linqiuming@gdufs.edu.cn
}

Received: May 6, 2019

doi:10.5296/ijl.v11i4.15229
Accepted: July 1, 2019

Published: August 7, 2019

URL: https://doi.org/10.5296/ijl.v11i4.15229

\begin{abstract}
This paper is aimed to provide a review about the studies on how people practice their agency in various types of discourse and to suggest the possible directions for future research. The paper begins with the introduction to different conceptualizations of human agency in philosophy and sociology. Next, it reviews how human agency has been explored in written discourses like textbooks, news stories and novels, as well as in spoken discourses including conversations and oral narratives. Then, it highlights the relationship between agency and systemic functional linguistics, as the latter has been effectively applied to analyzing human agency in discourse. The review shows that studies on discursive practice of agency have demonstrated the following features. First, human agency has been studied in various types of discourse with methodological biases. Second, the majority of the studies take a relatively static view towards agency within a particular discourse. Third, most of the studies are qualitative analysis to selected individual sentences or utterances. At the end of the paper, suggestions are given for further research based on the research gaps identified.
\end{abstract}

Keywords: Human agency, Discourse, Discursive practice, Systemic functional linguistics

\section{Introduction}

Human beings have the power to think and act. They have the capacity to make choices and impose their choices on the world. This kind of power or capacity is human agency, which is a very important notion in explaining various aspects of human cognition and action. It is "one of the cognitively fundamental factors which constitute an important part of our epistemic attitudes towards the outside world" (Yamamoto, 2000, p.2). Human agency is often manifested or implied by the language people use. Sociolinguists have expanded on notions of agency in the social sciences by considering the linguistic construction of agency. Al Zidjaly (2009, p.178) suggests that agency is also linguistic, explaining that "agency is best conceived as a collective process for negotiating roles, tasks, and alignments that takes 
place through linguistic...or nonlinguistic meditational means". In fact, linguistic anthropologists and sociolinguists have been viewing language as a form of social action and have looked for concrete linguistic examples of agentive or non-agentive social actions. They have examined specific discursive features to reveal how people construe themselves and their relations with the world. In this paper, we are going to review the studies on how people practice agency in their language, i.e. in various types of discourse. Before that, it is necessary to specify what human agency is.

\section{Conceptualizations of Agency}

According to the Oxford English Dictionary, the word "agent" in English was first used in 1471 when it was written in a treatise on alchemy, meaning "a force capable of acting on matter". Gradually it has been generally defined as a "person who or thing which acts upon someone or something; one who or that which exerts power; the doer of an action". Out of "agent" developed the word "agency". Agency can be found everywhere. When entities interact with each other and cause changes in each other, they can be identified as agents and patients. However, in the fields of philosophy and sociology, the word "agency" has a much narrower sense.

\subsection{Agency in Philosophy}

"Agency" is generally used to denote the "performance of intentional actions" in philosophy. This denotation can be traced back to ancient philosophers Hume and Aristotle, and related with modern philosophers Anscombe and Davidson (Schlosser, 2015). According to the "standard conception" that was established by Anscombe and Davidson, agency is an "intentional action initiated by the agent with mental representations". However, this conception of agency has been argued over the past few decades.

Agency as intentional action

Anscombe (1957) contends that "agency is an intentional act that results in a particular outcome; or it describes the process through which people intentionally change themselves or their situations through their own actions." Davidson (1971) states that "a man is the agent of an act if what he does can be described under an aspect that makes it intentional" (p.7). Both Anscombe and Davidson explain agency in terms of the intentionality of action. According to them, if an entity has the right functional organization, it has the capacity to act intentionally; if an entity has the capacity to act intentionally, it is able to exercise agency. Therefore certain desires, beliefs, and intentions of an entity would result in certain movement of the entity. According to this "standard conception", the exercise of agency consists in the performance of intentional actions or "the instantiation of the right causal relations between agent-involving states and events" (Davidson, 1963, 1971; Goldman, 1970; Brand, 1984; Bratman, 1987; Dretske, 1988; Bishop, 1989; Mele, 1992, 2003; Enç, 2003).

However, some scholars argue that actions are not mere happenings, so this conception cannot capture the nature of agency. They further claim that reasons should not be mental states or event, but facts or states of affairs, so reasons for actions are not the same as causes of actions (Dancy, 2000; Alvarez, 2010). 
Agency as initiation by the agent

The "standard conception" has argued that agency involves the agent's initiation of action, and the agent's mental states and events are the causation of this initiation. However, it has been controversial what this initiation is exactly caused by. According to desire-belief versions of the "standard conception", the agent's initiation is caused by the relevant desire-belief pairs (Goldman, 1970; Davidson, 1971; Dretske, 1988). According to more recent versions, however, the initiation is caused by the relevant intentions (Brand, 1984; Bratman, 1987; Bishop, 1989; Mele, 1992, 2003; Enç, 2003).

Opponents of the "standard conception" argue that an agent' initiation of action is not equal to acting with intentions or for reasons. They contend that an agent may exercise agency spontaneously for no reason and without any intention. Agency consists in the power of initiation, but that does not mean that the agent is activated by reasons or intentions (Ginet, 1990; O'Connor, 2000; Lowe, 2008). This alternative conception of agency denies any explanations of agency from the perspective of causal relations between mental states and events.

\section{Agency with mental representation}

The "standard conception" interprets agency in terms of mental representations, which are intentional mental states and events that have representational contents, such as the agent's desires, beliefs and intentions. Opponents of the "standard conception" argue that there are agents who do not have mental representations. Firstly, there are non-human agents that do not have desires, beliefs and intentions. Secondly, there are human agents who are not activated by intentional mental states and events. Thirdly, mental representations cannot account for all instances of agency (Chemero, 2009; Silberstein \& Chemero, 2011; Hutto \& Myin, 2014).

It follows that different levels of agency should be distinguished in philosophic discussion. The "standard conception" only explains the intermediate level - "intentional agency". There are higher or more advanced levels of agency, e.g. self-controlled, autonomous, and free agency. There are also lower or more primitive levels of agency which do not possess any mental representations.

\subsection{Agency in Sociology}

In social science, human agency is "the capacity of individuals to act independently and to make their own free choices" (Barker, 2005). A capacity implies the potential that a person has, instead of what he actually does. Therefore, when agency is said to be a capacity, it is regarded not as a set of actions, but as a potential within a person.

In similar ways, agency has been defined by different scholars: the "ability of individuals to exercise choice and discretion in their everyday practices" (Pickering, 1995), the "socio-culturally mediated capacity to act" (Ahearn, 2001), and the "capacity to initiate purposeful action that implies will, autonomy, freedom, and choice" (Lipponen \& Kumpulainen, 2011). Giddens (1984) emphasizes the transformative potential of agency. He 
believes that human agents have the capability to bring changes to their situation or environment. Feminist anthropology and subaltern studies have viewed agency as a desire for freedom, autonomy and the subversion of social norms (Mahmood, 2005).

In sociology, structure is often the concept in contrast to agency. Structure is those influential factors that prompt or restrict an agent's decisions or behaviors. These structural factors include social class, religion, gender, ethnicity, ability, customs, etc. Sewell (1992) discusses the dialectic relation between "agency" and "structure" by defining structure as "sets of mutually sustaining schemas and resources that empower and constrain social action and that tend to be reproduced by social action" (p.19). According to him, the current structures influence social actions by either empowering or constraining them. Meanwhile, the current structures can also be reshaped by social actions. The interactions between structures and social actions are achieved through human agency. "To be an agent means to be capable of exerting some degree of control over the social relations in which one is enmeshed, which in turn implies the ability to transform those social relations to some degree" (p.20). This capability is human agency. "Agency arises from the actor's knowledge of schemas, which means the ability to apply them to new contexts....agency arises from the actor's control of resources, which means the capacity to reinterpret or mobilize an array of resources in terms of schemas" (p.20). These accounts show that agency has its sources in virtual schemas and actual resources.

Stressing the reconstructive, (self-) transformative potentialities of human agency, Emirbayer and Mische (1998) re-conceptualize agency as "a temporally embedded process of social engagement, informed by the past (in its habitual aspect), but also oriented toward the future (as a capacity to imagine alternative possibilities) and toward the present (as a capacity to contextualize past habits and future projects within the contingencies of the moment)" ( $p$. 963). They believe that "actors are always living simultaneously in the past, future, and present, and adjusting the various temporalities of their empirical existence to one another (and to their empirical circumstances) in more or less imaginative or reflective ways....There are times and places when actors are more oriented toward the past, more directive toward the future, or more evaluative of the present. Actors may switch between and reflexively transform their orientations toward action, thereby changing their degrees of flexible, inventive, and critical response toward structuring contexts" (p. 1012). This temporal view provides a more comprehensive and dynamic perspective to agency, and gives a better understanding to the power that agents have to reproduce the structures with their actions.

\section{Agency in Various Discourses}

As mentioned above, linguistic anthropologists and sociolinguists view language not only as a set of formal structures, but also as "a form of social action, a cultural resource, and a set of socio-cultural practices" (Schieffelin, 1990, p.16). Ahearn (2001) suggests that scholars who are interested in agency should look closely at language and linguistic form. Through examining their language, e.g. the grammatical markers and syntactical patterns, we can better understand how people perform their identity and construct their agency. 


\subsection{Agency in Written Discourse}

A number of scholars have explored agency in written language. Oteiza and Pinto (2008) investigate how the history textbooks used in middle schools depict the dictatorships and subsequent transitions to democracy (1975-1978) in Spain and Chile. They employ transitivity analysis from Halliday's systemic functional linguistics to examine how participants and processes are represented in textbooks of the two countries. They find that the textbooks highlight some social actors while silencing others by using certain transitivity pattern to avoid assigning responsibility in the discourse. This is one of the main linguistic resources to objectivize and existentialize certain conflictive events so as to construct agency and provide explanations in textbooks.

Franzosi, De Fazio and Vicari (2012) investigate into newspaper stories of lynchings in Georgia (1875-1930) to examine the agency issue. Drawing upon corpus linguistics and computational linguistics, the researchers develop Quantitative Narrative Analysis (QNA), a computer-assisted tool, to collect 1,332 newspaper articles to build a large corpus, and to analyze these articles based on narrative grammars. This is an important methodological contribution to the operationalization and quantitative measurement of agency, as QNA has proved to be able to produce results that reveal meaningful patterns about actors and processes. However, QNA is incapable to capture the covert agents in discourse, so the researchers also adopt discourse analysis as a complimentary qualitative approach in their study. Through their discourse analysis, they find that passivization and nominalization are two major linguistic devices to deny agency in newspaper stories.

Hardstaff (2014) examines child agency in the 1976 novel Roll of Thunder, Hear My Cry by Mildred D. Taylor based on critical corpus linguistics and Halliday's systemic functional linguistics. The researcher focuses on how Cassie (the protagonist in the novel) takes control of and changes her environment. Altogether five characters and four chapters are selected for comparative analysis. The number and percentages of different process types used by the author are compared among Cassie and other characters in different chapters. The results show that Cassie's material agency is increasing chapter by chapter, and her verbal agency is also becoming stronger and stronger.

It should be noted that writing systems are generally assumed to affect, to some extent, the ways people make sense of themselves and others. In writing, people are more "capable of making lists, charting changes, categorizing everyday experiences, developing a new form of memory, and ensuring the transmission of memories between generations" (Ong, 1982). Furthermore, people make linguistics choices under more conscious control.

\subsection{Agency in Conversations}

Different from written texts, oral talks occur in a more spontaneous way. Assuming that agency is achieved in interactions, quite a few scholars have tried to observe agency in real-time conversations.

Strauss and Xiang (2006) investigate how agency is constructed by the ESL students through dialogs with their instructor in the writing conferences. The researchers have built a 
25,000-word corpus from ten writing conferences between the instructor and seven students. The dialogues are transcribed and then analyzed by conversation analysis, with a focus on turn-takings and stance-shifts. According their findings, the students' talks in earlier conversations seem to be uncertain, confused, negatively self-evaluated. As the writing conferences progress, students tend to be more confident and assertive by proposing solutions to problems and expressing more authorial ideas.

Miller (2010)'s study is based on a corpus of 18 interviews with small business owners who have immigrated to United States and explores how these ESL learners construct agency during their interaction with the interviewer. In their story worlds, the interviewees position themselves as agents, who make rational and responsible choices. Using both quantitative and qualitative analyses, the study identifies the linguistic devices used by the interviewees in the co-constructed interviews from a poststructuralist perspective.

Comparini (2013) collects 206 conflict episodes from 9 Spanish-speaking mother-child pairs to investigate the discursive construction of agency and social connection by using justifications in spontaneous mother--child conflict talk. Specifically, she examines the differences between mother and child in terms of the frequency of justifications used with one another, the contexts in which these justifications are used, and the self-other positioning by use of pronominal forms (including self vs. other references and different person forms). Her study suggests that the justifications with pronominal forms as positioning devices contribute to constructing agency and social relations with each another.

King (2014) explores the development of teenagers' sense of sexual agency through classroom conversations. The researcher audio-records and analyzes the interactions between the participants (students in a secondary school in New Zealand) when they are given a scenario for discussion during a sexuality lesson. Drawing upon poststructuralist discourse analysis, the study demonstrates that during the classroom conversations, girls are positioned as "asked" and boys as "asker". At the same time, girls are also positioned as "pursuer" and boys as "pursued". The researcher concludes that the discursive versions of agency are essential for youth sexual development.

\subsection{Agency in Oral Narratives}

Narratives, as a discursive form of acting in the world, play a central role in identity construction (Schiffrin, 1996). It performs social functions in people's lives. Every day people tell stories to create and perpetuate a sense of self. This is a sense of a continuous self - fusing one's past, future and present identities. People use daily stories to position themselves in certain identities. Constructivists view narratives as the narrators' interpretations of the social world. "They are not only tools for reflecting on people's lives, but constructive means for the creation of characters in space and time" (Bamberg \& Georgakopoulou, 2008). As one of the issues of identity, agency has also been investigated through interview-elicited narratives. Gender is one of the fields that linguistic anthropologists are most concerned with. Researchers seem to favor women in their agency study. There are studies on battered women (e.g. Hydén, 2005; Semaan, Jasinski \& Bubriski-McKenzie, 2013), single women (e.g. Reynolds, Wetherell \& Taylor, 2007), 
lesbians (e.g. Lieblich, Zilber \& Tuval-Mashiach, 2008), university female students (e.g. Jacques \& Radtke, 2012), female politician (e.g. Davids, 2011), etc. A common approach in all the research is what is termed "narrative inquiry", which is featured by one-to-one open-ended in-depth interviews, audio-recorded and later transcribed and searched for meaningful patterns in discourse. Researchers orient their analysis mostly on the content of the interviews, and explore women's construction of agency in the context of competing and changing social discourses. Different analytic tools in critical discursive psychology are applied, such as interpretative repertoires, ideological dilemmas, subject positions, etc. Various theories are drawn upon to interpret the interview data, including Foucault's notion of power relations, Butler's accounts on the paradox of subjection and post-feminism. There is also agency research on men. McKendy (2006) bases his research on life-story interviews with male prisoners who have committed violent crimes. He explores how the men construct their agency when they tell of stories about themselves. By closely examining the informants' wording and phrasing in their narratives, the researcher finds what he calls "narrative debris", such as pauses, inconsistencies, self-interruptions, repetition, etc. The study concludes that imprisonment not only means physical confinement, but also entails ideological and discursive confinement.

Applied linguists and language educators who are interested in learner identity or learner agency have also used narrative data in their studies. Barkhuizen (2013) suggests that language learning stories can reveal the process of second language acquisition, as well as the ever-changing socio-cultural features embedded in the process. Narratives of language learning experiences can shed light on the issues about learner agency or learner identity. In Qin (2015)'s investigation on a college student's English-learning trajectory, she adopts the narrative approach and finds that the relationship between agency and identity is non-linear while both play important roles in foreign language learning. The study argues that learners' construction of identities is strongly facilitated by agentive learning actions.

\section{Agency and Systemic Functional Linguistics}

Systemic functional linguistics (SFL) is a fine-grained approach to tease agency out in texts. From section 3.1 we learn that SFL has already been successfully applied in analyzing agency in written discourse (e.g. Oteiza \& Pinto, 2008; Hardstaff, 2014). According to Halliday (1975), language has three functions. The first is to "construe experience in terms of what is going on around us and inside us". The second is to "interact with the social world by negotiating social roles and attitudes". The third and final function is to "create messages with which we can package our meanings in terms of what is New or Given, and in terms of what the starting point for our message is, commonly referred to as the Theme". These three functions of language are referred to as "ideational", "interpersonal" and "textual" meta-functions respectively (Halliday, 1979).

Through its ideational meta-function, language provides an interpretation of human experience. People use language to talk about what they experience in the world, including things, people, events in the external world and feelings, attitudes, and thoughts in their internal world. The ideational function includes two sub-functions, the experiential and the 
logical. "From the experiential perspective, language comprises a set of resources for referring to entities in the world and the ways in which those entities act on or relate to each other. At the simplest level, language reflects our view of the world as "consisting of 'going-on' (verbs) involving things (nouns) which may have attributes (adjectives) and which go on against background details of place, time, manner, etc. (adverbials)" (Thompson, 2008, p.86). Thus language contains the meaning as organization of experience.

Identity or agency construction in narratives is concerned with how the speakers construe themselves, their experience and their environment. This is an experiential matter. In SFL, the experiential function is realized by transitivity patterns, which is a means of "conveying ideas about who acts, speaks, sees, and reflects, etc. in individual clauses"; an analysis of these patterns "helps readers understand human interactions in social contexts and can be used to uncover ideological meanings within them" (Nguyen, 2012, p.86). For example, active verbs can be used to perform a variety of processes and thus realize different types of agency. Transitivity analysis can give a careful examination to the linguistic features that help to constitute subjectivity and agency.

However, such a powerful micro-discourse analytic approach has been rarely applied to oral discourse. Barker and Galasinski (2001) are among the few to have brought oral narrative data into a close micro-linguistic analysis to deal with problems of agency. They interviewed local residents all aged over 70 in a border village in Poland, and collected their accounts about the events of the WWII. One of their research purposes was to examine how the conflict between Polish and Ukrainian inhabitants in Bircza was represented in terms of agents and patients, how Poles and Ukrainians were represented as 'doing things' or becoming engaged in events. After conducting transitivity analysis and ergative analysis to selected individual utterances, researchers found that the conflict was constructed as being of the Ukrainians' doing. Poles were reduced to passive participants.

\section{Conclusion \& Suggestions for Further Research}

To sum up, studies on discursive practice of agency have demonstrated the following features. First, agency has been studied in various types of discourse with methodological biases. SFL is mostly applied to analyzing agency in written discourse or prepared speech, but much less to spontaneous oral discourse. As for conversations, researchers are concerned more with the interactive features than with individual clause features. As for oral narratives, the most frequently used research method is narrative inquiry, which is based on content or thematic analysis.

Secondly, most studies take a relatively static view towards agency within a particular discourse. In fact, agency is dynamically constructed and reconstructed as the discourse develops. It may vary from clause to clause, instead of being consistent throughout the discourse. However, there is little research focusing on the fluctuations of agency. Furthermore, there is little longitudinal research to observe the changes of agency within an individual over a period of time. 


\section{Macrothink}

International Journal of Linguistics

ISSN 1948-5425

2019, Vol. 11, No. 4

Thirdly, most studies, especially of spoken discourses, are qualitative analysis to selected individual utterances. There is lack of quantitative research to show the general pattern of agency features throughout an oral discourse. Besides, computer-assisted analyses are seldom found for dealing with large volumes of oral discourse.

Therefore further research on agency in discourse may take a more dynamic view to investigate the fluctuations and changes of agency within an individual discourse, or across discourses by the same writer or speaker. Researchers may also try to develop various approaches, methods and tools to analyze agency in different types of discourses, so that a better understanding of discursive practices of human agency will be achieved.

\section{Acknowledgments}

The research is co-supported by a grant from Guangdong Province, China, for the key Project of Pragmatic Culture and Identity Construction (Grant Number 2018WCXTD002) and by a grant from the Ministry of Education, China, for the Project of Mainland Chinese Students' Adaptation to Universities in Hong Kong - the Perspective of Learner Autonomy (Grant Number 17YJA 880016).

\section{References}

Ahearn, L. (2001). Language and agency. Annual Review of Anthropology, 30, 109-137.

Al Zidjaly, N. (2009). Agency as an interactive achievement. Language in Society, 38(2), 177-200.

Alvarez, M. (2010). Kinds of Reasons: An Essay in the Philosophy of Action. Oxford: Oxford University Press.

Anscombe, G. (1957). Intention. Oxford: Basil Blackwell.

Bamberg, M., \& Georgakopoulou, A. (2008). Small stories as a new perspective in narrative and identity analysis. Text \& Talk, 28, 377-396.

Bamberg, M., De Fina, A., \& Schiffrin, D. (2011). Discourse and identity construction. In S. Schwartz, K. Luyckx \& V. Vignoles (Eds.), Handbook of identity theory and research. Berlin/New York: Springer Verlag.

Barker, C. (2005). Cultural Studies: Theory and Practice. London: Sage.

Barker, C., \& Galasiński, D. (2001). Cultural Studies and Discourse Analysis: A Dialogue on Language and Identity. London: Sage.

Barkhuizen, G. (2013). Narrative Research in Applied Linguistics. Cambridge: Cambridge University Press.

Bishop, J. (1989). Natural Agency: An Essay on the Causal Theory of Action. Cambridge: Cambridge University Press.

Brand, M. (1984). Intending and Acting: Toward a Naturalized Action Theory. Cambridge, MA: MIT Press. 


\section{Macrothink}

International Journal of Linguistics

ISSN 1948-5425

2019, Vol. 11, No. 4

Bratman, M. (1987). Intention, Plans, and Practical Reason. Cambridge, MA: Harvard University Press.

Chemero, T. (2009). Radical Embodied Cognitive Science. Cambridge, MA: MIT Press.

Comparini, L. (2013). The use of justifications in the linguistic construction of agency and social connection in Latina mother--child conflict. Journal of Pragmatics, 57, 57-67.

Dancy, J. (2000). Practical Reality. Oxford: Oxford University Press.

Davids, T. (2011). The micro dynamics of agency: Repetition and subversion in a Mexican right-wing female politician's life story. European Journal of Women's Studies, 18, 155-168.

Davidson, D. (1963). Actions, reasons, and causes, reprinted in Davidson (1980), 3-20.

Davidson, D. (1971). Agency, reprinted in Davidson (1980), 43-61.

Dretske, F. (1988). Explaining Behavior: Reasons in a World of Causes. Cambridge, MA: MIT Press.

Emirbayer, M., \& Mische, A. (1998). What Is agency?. American Journal of Sociology, 103, 962-1023.

Enç, B. (2003). How We Act: Causes, Reasons, and Intentions. Oxford: Oxford University Press.

Franzosi, R., De Fazio, G., \& Vicari, S. (2012). Ways of measuring agency: an application of quantitative narrative analysis to Lynchings in Georgia (1875-1930). Sociological Methodology, 42, 1-42.

Giddens, A. (1984). The Constitution of Society: Outline of the Theory of Structuration. Berkeley and Los Angeles: University of California Press.

Ginet, C. (1990). On Action. Cambridge: Cambridge University Press.

Goldman, A. (1970). A Theory of Human Action. Englewood Cliffs, NJ: Prentice-Hall.

Halliday. M. A. K. (1975). Learning How to Mean. London: Edward Arnold.

Halliday. M. A. K. (1979). Modes of meaning and modes of expression: types of grammatical structure and their determination by different semantic functions. In Allerton, D.J. Edward Carney \& David Addcroft (Eds.), Function and Context in Linguistics Analysis. Cambridge: Cambridge University Press.

Hardstaff, S. (2014). "Papa said that one day I would understand": Examining child agency and character development. Children's Literature in Education. https://doi.org/10.1007/s10583-014-9231-1

Hutto, D., \& Myin, E. (2014). Neural representations not needed: No more please, please. Phenomenology and the Cognitive Sciences, 13(2), 241-256. 


\section{Macrothink}

International Journal of Linguistics

ISSN 1948-5425

2019, Vol. 11, No. 4

Hydén, M. (2005). I must have been an idiot to let it go on': agency and positioning in battered women's narratives of leaving. Feminism \& Psychology, 15, 169-188.

Jacques, H., \& Radtke, H. (2012). Constrained by choice: Young women negotiate the discourses of marriage and motherhood. Feminism \& Psychology, 22, 443-461.

King, B. (2014). Inverting virginity, abstinence, and conquest: Sexual agency and subjectivity in classroom conversation. Sexualities, 17, 310-328.

Lieblich, A., Zilber, T., \& Tuval-Mashiach, R. (2008). Narrating human actions: The subjective experience of agency, structure, communion, and serendipity. Qualitative Inquiry, $14,613-631$.

Lipponen, L., \& Kumpulainen, K. (2011). Acting as accountable authors: Creating interactional spaces for agency work in teacher education. Teaching and Teacher Education, 27, 812-819.

Lowe, E. (2008). Personal Agency: The Metaphysics of Mind and Action. Oxford: Oxford University Press.

Mahmood, S. (2005). Politics of Piety: The Islamic Revival and the Feminist Subject. Princeton: Princeton University Press.

McKendy, J. (2006). "I'm very careful about that": narrative and agency of men in prison. Discourse Society, 17, 473-502.

Mele, A. (1992). Springs of Action: Understanding Intentional Behavior. Oxford: Oxford University Press.

Mele, A. (2003). Motivation and Agency. Oxford: Oxford University Press.

Miller, E. R. (2010). Agency in the making: adult immigrants' accounts of language learning and work. TESOL Quarterly, 44, 465-487.

Murphey, T., \& Carpenter, C. (2008). The seeds of agency in language learning histories. In P. Kalaja, V. Menezes, \& A. M. F. Barcelos (Eds.), Narratives of Learning and Teaching EFL (pp. 17-34). Basingstoke, UK: Palgrave Macmillan.

Nguyen, H. (2012). Transitivity analysis of 'Heroic Mother' by Hoa Pham. International Journal of English Linguistics, 2, 85-100.

O'Connor, T. (2000). Persons and Causes: The Metaphysics of Free Will. Oxford: Oxford University Press.

Ong, W. (1982). Orality and Literacy: The Technologizing of the Word. London and New York: Methuen.

Oteiza, T., \& Pinto, D. (2008). Agency, responsibility and silence in the construction of contemporary history in Chile and Spain. Discourse Society, 19, 333-358. 


\section{Macrothink}

International Journal of Linguistics

ISSN 1948-5425

2019, Vol. 11, No. 4

Pickering, A. (1995). The Mangle of Practice: Time, Agency, and Science. Chicago: University Chicago Press.

Qin, L. (2015). Relationships between English learner agency and identity in socio-cultural perspective. Foreign Language Education, 36, 60-64.

Schieffelin, B. (1990). The Give and Take of Everyday Life: Language Socialization of Kaluli Children. Cambridge: Cambridge University Press.

Schiffrin, D. (1996). Narrative as self-portrait: The sociolinguistic construction of identity. Language in Society, 25, 167-203.

Schlosser, M. (2015). Agency, The Stanford Encyclopedia of Philosophy, Edward N. Zalta (Ed.). Retrieved from https://plato.stanford.edu/archives/fall2015/entries/agency/

Semaan, I., Jasinski, J., \& Bubriski-McKenzie, A. (2013). Subjection, subjectivity, and agency: The power, meaning, and practice of mothering among women experiencing intimate partner abuse. Violence Against Women, 19, 69-88.

Sewell, W. (1992). A theory of structure: duality, agency, and transformation. American Journal of Sociology, 98, 1-29.

Silberstein, M., \& Chemero, A. (2011). Dynamics, agency and intentional action. Humana Mente, 15, 1-19.

Strauss, S., \& Xiang, X. (2006). The writing conference as a locus of emergent agency. Written Communication, 23, 355-396.

Thompson, G. (2008). Introducing Functional Grammar. Beijing: Foreign Language Teaching and Research Press.

Yamamoto, M. (2006). Agency and impersonality: Their linguistic and cultural manifestations. Amsterdam: Benjamins.

\section{Copyrights}

Copyright for this article is retained by the author(s), with first publication rights granted to the journal.

This is an open-access article distributed under the terms and conditions of the Creative Commons Attribution license (http://creativecommons.org/licenses/by/4.0/ 